Bei einem Neunjährigen

\title{
Fahrradsturz mit Folgen
}

Ein neunjähriger Junge war bei einem Fahrradsturz mit dem Oberbauch gegen seinen Fahrradlenker geprallt und wurde mit einem stumpfen Bauchtrauma in die Rettungsstelle aufgenommen. Die klinischen Laborparameter, wie auch die initiale klinische Untersuchung waren bis auf starke abdominelle Schmerzen unauffällig.
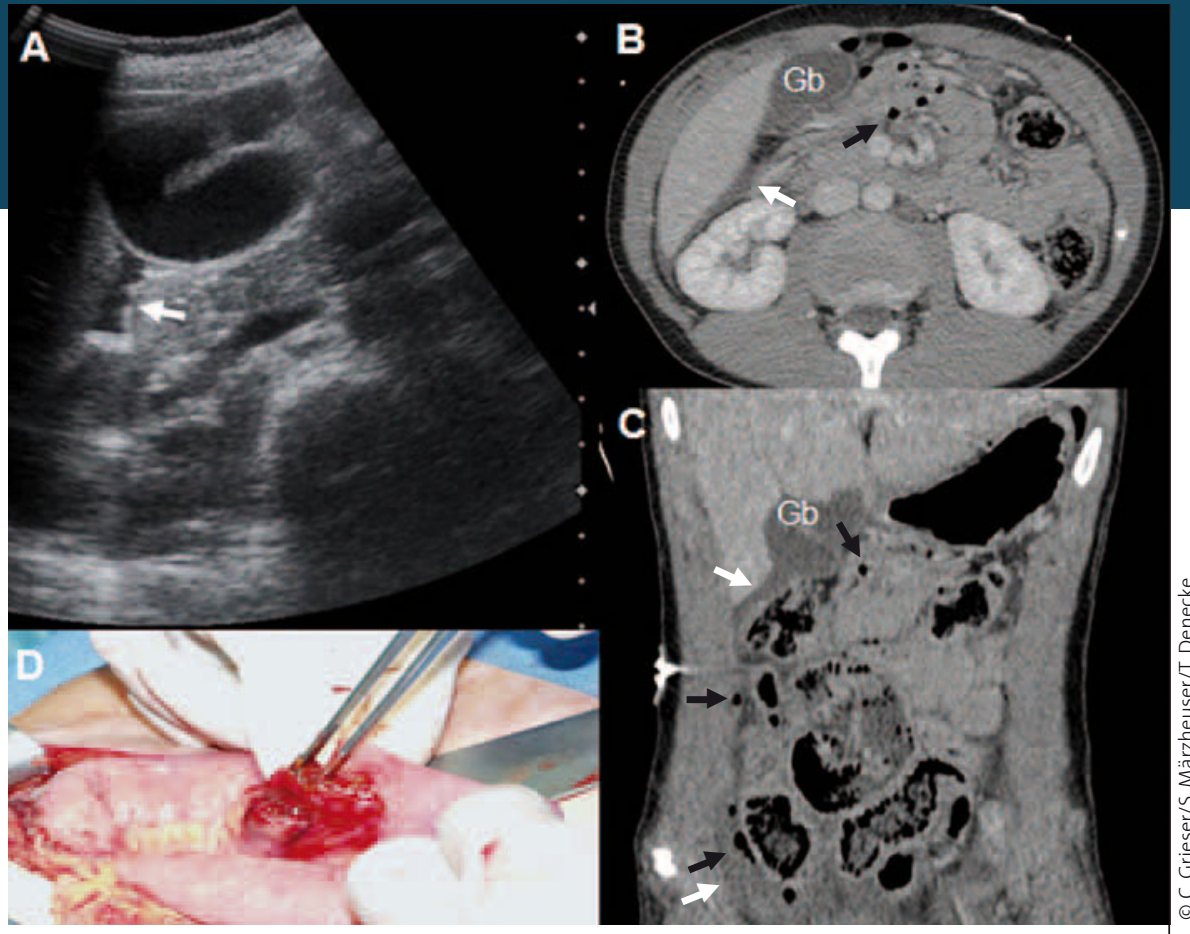

$\mathrm{Gb}=$ Gallenblase

— Eine Abdomensonografie zeigte mäßig freie Flüssigkeit, besonders perihepatisch, perilienal und interenterisch (Abbildung A, weißer Pfeil) ohne eine direkte Parenchymverletzung. In der Computertomografie des Abdomens fand sich zusätzlich freie retro- und intraperitoneale Luft im Bereich des Duodenums und des terminalen lleums (Abbildung B, C; weiße Pfeile) und ein Hämatom im Bereich der Mesenterialwurzel. Es wurde somit der Verdacht auf eine Dünndarmruptur gestellt, die sich in der sofort durchgeführten explorativen Laparotomie bestätigte. Es fand sich eine Perforation des terminalen lleums von zirka 0,2 cm Länge mit einem Serosadefekt von $3 \mathrm{~cm}$ Länge (Abbildung D), die operativ versorgt wurde. Nach zweitägiger Überwachung auf der Intensivstation ohne zusätzliche Komplikationen konnte der kleine Patient am dritten postoperativen Tag in stabilem Zustand auf die periphere Station verlegt und nach kurzer Zeit beschwerdefrei entlassen werden.

Dünndarmperforationen sind bei Kindern mit einem stumpfen Bauchtrauma zwar eher selten, treten aber im Vergleich zu den übrigen Darmverletzungen im Rahmen dieses Traumageschehens am häufigsten auf. Gefährlich bei dieser Verletzung sind die teils erst verzögert demaskierten Symptome einer sekundären intraperitonealen Hämorrhagie, Peritonitis oder Sepsis, die lebensbedrohlich sein können.
Die primär diagnostische Vorgehensweise beinhaltet neben der klinischen und laborchemischen Untersuchung eine Sonografie des Abdomens, die Aufschluss über mögliche freie Flüssigkeit und eine Verletzung der parenchymatösen Organe gibt. Zusätzlich kann trotz Strahlenexposition jedoch eine Computertomografie des Abdomens notwendig sein, falls die initiale Sonografie nicht komplett Aufschluss über das jeweilige Verletzungsmuster gibt.

Keywords: perforation of the small bowel

- Dr. med. Christian Grieser', Dr. med. Stefanie Märzheuser², Dr. med. Timm Denecke ${ }^{1}$

Charité Universitätsmedizin Berlin, Campus Virchow-Klinikum,

(1) Klinik für Strahlenheilkunde, (2) Klinik für Kinderchirurgie, Augustenburger Platz 1, D-13353 Berlin

Info

Unsere Blickdiagnosen finden Sie auch im Internet unter:

http://www.springermedizin.de/ blickdiagnosen-aus-der-praxis/307330.html 